Article

\title{
Development of BIM-Based Risk Rating Estimation Automation and a Design-for-Safety Review System
}

\author{
Yongha Lee ${ }^{1}$, Inhan Kim ${ }^{1}$ and Jungsik Choi ${ }^{2, *}$ \\ 1 Department of Architecture, Kyung Hee University, Yongin-si 17104, Korea; stays1006@gmail.com (Y.L.); \\ ihkim@khu.ac.kr (I.K.) \\ 2 Major in Architecture IT Convergence Engineering, Division of Smart Convergence Engineering, \\ Hanyang University, Ansan-si 15588, Korea \\ * Correspondence: jungsikchoi@hanyang.ac.kr; Tel.: +82-31-400-5962
}

Received: 6 May 2020; Accepted: 2 June 2020; Published: 5 June 2020

\begin{abstract}
Various laws and guidelines on designing for safety have been developed world-wide, and these were used to identify risks at construction sites in advance through qualitative and quantitative safe management. In other words, attention is being paid to safe management based on design drawings and models rather than field visits. It was predicted that the introduction of the concept of design-for-safety would minimize risk at construction sites through safe management in the design phase. This is because the efficiency and reliability of such a strategy has been demonstrated in various cases abroad. However, domestic design-for-safety suggests a very limited range of evaluation items, so there is a limit to using such strategies in construction sites. Building information modeling (BIM) technology is attracting attention in situations when safe management must also be based on design proposals. Although previous studies on the identification of falling disasters and automatic identification of hazards have been conducted, these studies only deal with a limited range of items for identifying risk items. For example, BIM-based risk extraction, which is limited to falling disasters, is only at the level of risk recognition that can be derived based on the process table, and evaluation is not made accordingly. It is difficult to assess the overall disaster risk in many of the items required for risk rating estimation. In this paper, we solve the above problems by deriving a BIM-based risk rating estimation scenario based on the disaster scenario for automating BIM-based risk rating estimation, and we developed an evaluation system using this method. The BIM-based risk rating estimation methodology was presented through BIM-based hazard extraction, evaluation of requirement information, evaluation item selection, and using the evaluation system in a design-for-safety review.
\end{abstract}

Keywords: building information modeling (BIM); design for safety (DfS) review; hazard prevention; risk rating estimation; safety management

\section{Introduction}

Despite the increasing interest in reducing safety accidents at domestic construction sites, there is a limit to existing safety management techniques. At present, the main safety management measures of construction sites in Korea are focused on risk assessments based on site inspections and existing safety accident cases. The missing evaluation items and control measures are supplemented and evaluated based on the experience and supervision of safety inspectors or other experts. So, different safety management results are achieved depending on the site and expert, which undermines the consistency of the safety management plan and reduces the objectivity of the evaluation results. Particularly in the case of domestic risk assessment, different risk assessments are made, and quantitative evaluation results are derived and based on the risk level to establish countermeasures for risk control. To compensate 
for this, the concept of "design-for-safety" has been introduced under the leadership of domestic and foreign governments to make efforts to efficiently and safely manage construction sites.

Design-for-safety decreases the risks that can occur during the life cycle of a building in the design phase by deriving hazards in advance and conducting a risk assessment. To this end, the government is trying to introduce this concept through legislation on guidelines, separate application cases, and related laws. In Korea, the construction industry provides guidance and application examples to support the design-for-safety review work, and continues to promote site-based design-for-safety. However, due to the introduction of a schedule-driven system and a lack of publicity, it has rarely been applied directly at the construction site until now. In addition, the design-for-safety review model for disasters that can occur in limited construction is reviewed for design-for-safety review, such as fall from height, hit by equipment etc., and much effort is being made to achieve safety management through risk assessment for design-for-safety reviews.

The concept of design-for-safety was introduced to remove risks by managing disasters occurring at construction sites beginning in the design stage. To achieve consistent safety management measures, building information modeling (BIM)-based hazard recognition and risk assessment are conducted to automate risk rating calculations. To this end, we studied the design-for-safety concept and analyzed the cases that are actually applied to identify the problems of domestic design-for-safety reviews and solve the problems of existing risk assessment. To simplify the risk assessment methodology of the existing design-for-safety approach and to make the evaluation consistent, common factors were extracted based on foreign cases, and the required evaluation items were derived first. The risk assessment was then simplified based on these results. In addition, a method of extracting hazards was derived to automate risk rating estimation. Based on this, the hazards that can occur at the construction site were extracted through macro risk assessment, and the weights of the severity, frequency coefficient, and control measures for risk rating estimation were calculated. Using this method, we will automate risk assessment using BIM-based risk assessment.

\section{Status and Literature Review}

\subsection{Review of Risk Assessment Technique}

Risk assessments refer to the process of determining the risk level by estimating the hazards in the safety management process and determining whether to allow the risks based on the results. In other words, risk assessment is a process in which hazards that may occur in a workplace are detected in advance, risks are estimated, and measures are taken according to the magnitude of the risks. In this process, the safety level is managed in the workplace through a process of establishing, reflecting, and documenting mitigation measures in accordance with the evaluation results of hazards that may occur in the workplace through the calculation of the risk level [1,2].

Risk assessment is divided into two types: quantitative and qualitative. For qualitative evaluation, there are driving analysis techniques, checklist techniques, and what-if. Quantitative evaluation methods include fault tree analysis (FTA), event tree analysis (ETA), and failure mode and effect analysis (FMEA). Among these, quantitative risk assessment is conducted in Korea [3,4]. Quantitative risk assessment follows the evaluation model of MIL-STD-882E, a program used for safety management at the Pentagon [5]. It describes how to recognize risks required for quantitative evaluation. To discriminate the risk, the risk is expressed according to the severity coefficient of the hazard and a coefficient associated with the likelihood of occurrence per unit time. The FMEA method is the most commonly used among risk analysis methods.

Risk assessment represents risk through qualitative/quantitative evaluation methods and is a measure for managing human/physical disasters that may occur in the workplace. The design-for-safety review is a concept to implement more accurate and efficient safety management by preemptively managing the risks that may occur at the construction site by conducting risk assessment and risk estimation in the design stage. It provides a risk assessment template, a method for recognizing 
hazards, and examples of risk estimation so that safety inspectors can perform consistent and objective risk assessment. Work is therefore performed according to the risk level of the work based on the calculated risk level. However, the missing tasks and requirements should be supplemented through consultation with experts due to limitations in the specified items and contents [6,7]. In this process, different evaluation results are displayed depending on the experience and supervision of the safety supervisor, and many efforts are being made at home and abroad to address this problem.

\subsection{Review of Design-for-Safety}

Design-for-safety is a concept established by Levitt and Samelson (1982) [8]. This concept extends the scope of the safety management subject to participants in the design process by conducting a risk assessment on the hazards that may occur for workers in the construction phase. This risk assessment is conducted in the design alternative creation process. In other words, during the design process, the hazards that may occur in the construction process or the life cycle of the building are detected based on design alternatives. Safety management of the construction site is carried out by reducing or eliminating risks or hazards. In the design phase, it is assumed that the hazards that may occur in the construction site are preliminary risk assessments, and the safety management of each hazard is the main purpose. To this end, the concept is introduced in different forms, being led by governments at home and abroad. Table 1 below summarizes the design-for-safety information for various countries.

Table 1. Design-for-Safety review cases.

\begin{tabular}{|c|c|c|}
\hline Country & Name & Criteria \\
\hline Korea & Design-for-safety (DfS) & $\begin{array}{l}\text { Design-for-safety Checking Manual (2017) [9] } \\
\text { Case study on Design-for-Safety Review Report in } 2018 \text { (2019) [10] }\end{array}$ \\
\hline U.S.A. & $\begin{array}{l}\text { Prevention through Design (PtD) } \\
\text { Design for Construction Safety (DfCS) }\end{array}$ & $\begin{array}{l}\text { Leadership in Energy and Environmental Design (LEED) Credit, [11] } \\
\text { Sustainable Construction Safety and Health (SCSH) Rating System (2006) [12] }\end{array}$ \\
\hline U.K. & Construction Design Management (CDM) & $\begin{array}{l}\text { Workplace health, safety and welfare (1992) [13], } \\
\text { Managing health and safety in construction (2015) [14], } \\
\text { Health and safety in construction (2006) [15], } \\
\text { Construction Phase Plan (CDM2015) [16] }\end{array}$ \\
\hline Singapore & $\begin{array}{c}\text { Design-for-safety, } \\
\text { GUIDE Process, } \\
\text { Construction Safety Audit Scoring System } \\
\text { (ConSASS) }\end{array}$ & $\begin{array}{l}\text { Guidelines on Design-for-Safety in Buildings and Structures (2008) [17], } \\
\text { Workplace Safety and Health Guidelines: Design-for-Safety (2016) [18], } \\
\text { A Guide to the Construction Safety Scoring Audit System (2013) [19], } \\
\text { Construction Safety Audit Scoring System Audit Checklist (2007) [20] }\end{array}$ \\
\hline Hong Kong & Design-for-Safety & $\begin{array}{l}\text { Guidance notes of Design-for-Safety (2013) [21], } \\
\text { Worked examples of Design-for-Safety (2013) [22] }\end{array}$ \\
\hline Australia & Safe Design & $\begin{array}{l}\text { Guidance on the principles of safe design for work (2006) [23], } \\
\text { Safe design of structures code of practice (2014) [24] }\end{array}$ \\
\hline
\end{tabular}

To introduce the concept of design-for-safety, other countries have distributed guidelines and regulations from the past and established infrastructure to institutionalize design-for-safety and apply it in practice. However, in Korea, it has been introduced relatively recently compared to other countries, and there are very few guidelines for infrastructure construction. In the U.S., PtD aims to introduce design-for-safety assessments through 2020 in connection with Leadership in Energy and Environment Design (LEED) credits, and design-for-safety reviews based on risk assessment are conducted through separate checklists in the UK, Singapore, Hong Kong, and Australia. In other words, to supplement the design-for-safety review, the existing risk assessment system is modified and supplemented for use in the review. The design-for-safety review work in Korea is also conducted based on the existing risk assessment system, and the application stage has been extended to the design stage to implement safety management at the construction site through risk assessment in the design stage [9]. However, since the fundamental objective of this paper is to provide a review through risk assessment to solve the problem of objectivity of the existing risk assessment, design-for-safety review guidelines used abroad are distributed and standards for risk assessment and hazard identification are provided. This serves the overall goal of providing an objective design-for-safety review. 


\subsection{Domestic and Overseas Design-for-Safety Review}

Various concepts related to design-for-safety, such as Prevention through Design (PtD), Design for Safety (DfS), Construction Safety Audit Scoring System (ConSASS), and safe design, have been developed and applied by government agencies. The application of each design stage, work items at each stage, and methods for recognizing hazards are provided to conduct risk assessment on hazards in an effort to exclude the subjectivity of the safety supervisor. To ensure consistent risk assessment, efforts are made to minimize reliance on experts during the calculation of risk by providing evaluation templates and risk rating criteria or hazards for each country. Table 2 below summarizes the items for each country required for design-for-safety reviews or risk assessments.

The UK and Australia provide checklists and risk lists to conduct risk management at construction sites through qualitative risk assessments, and do not employ quantitative evaluation indicators such as risk ratings and manage risks according to pre-classified hazards. Although it is possible to recognize the hazards consistently by checklist, the risk assessment of each disaster is left to the safety supervisor, and subjective risk assessment is conducted. In the risk assessment process, a qualitative risk assessment that measures and evaluates a simple risk level, rather than a quantitative indicator, may involve the supervisor's supervision during the risk recognition and risk assessment phase. In other words, this study derives the results of hazard recognition and risk rating calculation based on quantitative risk assessment for objective and consistent risk assessment by excluding supervisor supervision. In addition, the United States and Singapore carry out quantitative risk assessment and qualitative assessment together to implement integrated safety management.

\subsubsection{U.S.-Prevention through Design}

The U.S. design-for-safety review was introduced under the term PtD and was introduced to reduce the risks in construction projects from the design stage. This concept was introduced by organizing partnerships in each field under the supervision of government agencies such as the Center for Disease Control and Prevention (CDC) and OSHA (Occupational Safety \& Health Administration). In addition, pilot credits were distributed by adding PtD-related evaluation items to LEED credit items $[11,25]$. Items for PtD review were provided so that there was no great difficulty in acquiring information on $\mathrm{PtD}$ considerations for each situation. In addition, efforts are being made to introduce this concept, such as distributing separate educational software to recognize hazards in the workplace.

Among them, construction hazard prevention through design (CHPtD) is used to identify hazards in the construction site in advance, and risks are managed through qualitative evaluation. In addition, CHPtD implements integrated safety management of construction sites in the U.S. through quantitative risk assessment such as the SCSH rating system and the MIL-STD-882E model. In addition, they are focusing on BIM as an objective safety management tool, and several studies have been conducted on BIM [26,27]. For example, a study was conducted on how to recognize the hazards of a fall disaster using a BIM model [28], and another study focused on the analogy of a disaster that could occur in scaffolding work using schedule data $[29,30]$. The result is a simulation-level study of control measures. However, there are insufficient research cases on how to directly use it for risk assessment or PtD review.

\subsubsection{U.K., Europe-Construction Design Management}

The United Kingdom has shown great interest in safety management since the past, and several guidelines and checklists have been developed and distributed. Among them, the concept of CDM was introduced to expand the scope of safety management subjects from designers to users to implement safety management between building life cycles. To this end, various guidelines have been distributed to increase the effectiveness of safety management by providing respective checklists and requirements for construction project participants, such as designers, contractors, etc. [13-15]. 
Table 2. Quantitative/qualitative risk assessment classification by country.

\begin{tabular}{|c|c|c|c|}
\hline Country & Requirements for Assessment & Evaluation Items & Evaluation Method \\
\hline U.S.A. & SCSH Rating System & $\begin{array}{c}\text { Project team selection } \\
\text { Safety and health in contracts } \\
\text { Safety and health professional } \\
\text { Safety and health commitment } \\
\ldots \\
\text { Industrial hygiene practice }\end{array}$ & Quantitative Assessment \\
\hline \multirow[t]{2}{*}{ U.K. } & Orange List - Presence of Hazard (Yes/No) & $\begin{array}{c}\text { Fall from height } \\
\text { Collapse of excavations } \\
\text { Collapse of structures } \\
\text { Exposure to building dust } \\
\text { Exposure to asbestos } \\
\text { Ectivities or workers requiring supervision } \\
\text { Electricity } \\
\text { Risk to members of the public, the client and others } \\
\text { Other dangers on site }\end{array}$ & \multirow[t]{2}{*}{ Qualitative Assessment } \\
\hline & Risk Assessment template & $\begin{array}{c}\text { Hazard } \\
\text { Victim type } \\
\text { Injury scenario } \\
\text { Control measure already applied } \\
\text { New control measure } \\
\text { Risk management agent } \\
\text { Date } \\
\end{array}$ & \\
\hline \multirow[b]{2}{*}{ Singapore } & $\begin{array}{c}\text { Design-for-safety } \\
\text { (GUIDE-1:Concept Design Review) }\end{array}$ & $\begin{array}{c}\text { Solid (e.g., soil profile, foundation, etc.) } \\
\text { Public (e.g., traffic, etc.) } \\
\text { Services (e.g., underground service, etc.) } \\
\text { Others (identifying the method, identifying the foreseeable hazards, etc.) }\end{array}$ & \multirow[b]{2}{*}{ Qualitative Assessment } \\
\hline & $\begin{array}{c}\text { Design-for-safety } \\
\text { (GUIDE-2: Detailed Design, Maintenance and } \\
\text { Repair Review) }\end{array}$ & $\begin{array}{l}\text { Prefabrication (e.g., steel structures, cutting of steel members, welding, etc.) } \\
\text { Heavy lifting (e.g., foundation, work process, case scenarios, etc.) } \\
\text { Falling from height } \\
\text { Emergency route } \\
\text { Health hazards } \\
\text { Weather }\end{array}$ & \\
\hline
\end{tabular}


Table 2. Cont.

\begin{tabular}{|c|c|c|c|}
\hline Country & Requirements for Assessment & Evaluation Items & Evaluation Method \\
\hline & $\begin{array}{c}\text { Design-for-safety } \\
\text { (GUIDE-3: Pre-Construction Review) }\end{array}$ & $\begin{array}{c}\text { Temporary works and sequencing (e.g., safer means of access or egress, } \\
\text { work process, scheduling, effect on adjacent structures during removal, etc.) } \\
\text { Specialist design (e.g., safety concerns, alternative safe work, etc.) } \\
\text { Others }\end{array}$ & \multirow{3}{*}{ Quantitative Assessment } \\
\hline & Risk Assessment Template & $\begin{array}{c}\text { Design consideration } \\
\text { Risks } \\
\text { Hazard identified } \\
\text { Risk assessment (severity, likelihood, risk level) } \\
\text { Can be excluded by design } \\
\text { Control measures } \\
\text { Residual risk level (severity, likelihood, risk level) } \\
\text { Future review required? }\end{array}$ & \\
\hline & $\begin{array}{l}\text { ConSASS } \\
\text { (S-Score) }\end{array}$ & $\begin{array}{l}\text { List of hazards (fall from height, communication, slip and fall, collapse of } \\
\text { structures, hit by object, etc.) } \\
\text { ConSASS audit checklist (e.g., Osh policy, etc.) } \\
\ldots\end{array}$ & \\
\hline Australia & Safe Design & $\begin{array}{c}\text { Siting of structure (e.g., proximity to adjacent roads, surrounding land use, } \\
\text { demolition of existing assets, etc.) } \\
\text { High consequence hazards } \\
\text { System of work (e.g., rapid construction technique, materials, hazardous } \\
\text { manual tasks, etc.) } \\
\text { Environmental condition } \\
\text { Incident mitigation } \\
\ldots\end{array}$ & Qualitative Assessment \\
\hline Hong Kong & Design-for-safety Review template & $\begin{array}{c}\text { Activity } \\
\text { Risk and impacts } \\
\text { Risk level } \\
\text { Hazard resolved (yes/no) } \\
\text { Necessity to notify contractor (yes/no) }\end{array}$ & Quantitative Assessment \\
\hline
\end{tabular}


CDM provides an orange list to implement safety management at the construction site, which summarizes the contents of accidents and diseases that may occur at the construction site, and provides a Yes/No checklist for each item. CDM provides an orange list to implement safety management at the construction site, which summarizes the contents of accidents and diseases that may occur at the construction site, and provides a Yes/No checklist for each item [16]. However, even though the orange list and safety management plans are provided, the contents are limited to some disasters (fall, collapse, exposure to toxic substances), making it difficult to implement integrated safety management at construction sites where multiple disasters occur. In addition, a risk assessment template is provided, and since qualitative evaluation items are mainly written, there is a high probability of showing different evaluation results depending on the safety inspector. For example, when conducting a risk assessment for a disaster, it is difficult to produce a consistent review result because there are no clear standards for preparing the environment, countermeasures, etc.

In addition, the ECC (European Economic Community) intends to introduce the concept of Safe by design, but it is difficult to be used in construction sites because it focuses on manufacturing. In Ireland, the design-for-safety concept remains in the early stages of introduction, and it is difficult to utilize the reference case of this study due to the lack of guidelines or laws.

\subsubsection{Singapore-Design-for-Safety, ConSASS}

Singapore introduced the concept of design-for-safety and distributes related guidelines to achieve safety management during the life cycle of buildings through risk assessment at each design stage. To this end, they provide checklists and risk assessment templates for each GUIDE process, i.e., GUIDE-1, 2, and 3, and conduct integrated risk assessment through qualitative and quantitative risk assessment through checklists $[17,18]$. Consistent risk assessment is performed by providing information on tasks required during safety management, such as methods and items for recognizing hazards. Safety management of construction projects is performed by specifying the subject of risk management, such as reduction due to design changes and countermeasures against contractors. In addition to the safety management method that uses the existing risk assessment model, there is a separate safety assessment system known as ConSASS $[19,20]$. Twenty-three types of hazards that can occur in construction sites are provided, and safety is scored by assigning weights to each control measure. In addition, safety management of construction projects is implemented by compulsory submission of scoring results according to the ConSASS checklist during the licensing process. To ensure safety management occurs in the design stage, integrated safety management of construction projects is achieved through the development and introduction of conventional risk assessments such as design-for-safety and evaluation methods specific to the Singapore construction environment such as ConSASS. In other words, Singapore has implemented a safety assessment model unique to Singapore in addition to the existing safety management measures to achieve a consistent risk assessment by complementing each other.

\subsubsection{Hong Kong—Design-for-Safety}

Hong Kong introduced the concept of design-for-safety and distributed related guidelines and application casebooks, including guidelines that considered field applicability based on examples [22]. Each hazard recognition list and risk level for each item were specified, and detailed guidelines for design safety review, such as application items and review items for each design, are provided [21]. In addition, based on the risk assessment table of the $3 \times 3$ matrix, risk management is performed according to the categories of allowable/semi-acceptable/non-acceptable classes by classifying them into three classes as well as the risk level. Unlike in the U.S. and Singapore, quantitative evaluation is mainly performed, and management of the tasks occurring during the design-for-safety review is performed through considerations and checklists according to the hazards for each design entity. Although a checklist is provided for business management for each group (i.e., contractor/constructor/designer), 
it is not used in the risk assessment stage of construction sites. Risk management based on the risk recognition list and safety management using the existing risk assessment model are performed.

\subsubsection{Korea一Design-for-Safety}

Domestic design-for-safety was introduced in 2017 through related laws and guidelines $[9,10]$. This concept was introduced in accordance with the existing concept of design-for-safety, which extends the scope of the existing safety management measures to the design stage, but due to its hasty introduction, the utilization in actual construction projects is low [31]. One reason for this is that the distributed guidelines are ambiguous and do not directly replace the construction project's safety management work. For example, in overseas construction projects, they provide a risk assessment method, a hazard recognition method, and a hazard checklist for each disaster to provide a consistent design-for-safety review task. Thus, quantitative and qualitative evaluation of safety management elements that could not be reviewed in the existing design stage is achieved. Instead, the design-for-safety review in Korea provides instructions on the work based on the participant's occupation in the design stage and an evaluation system for risk assessment, but the content is not clear. As an example, in the case of the risk assessment coefficient table and the evaluation template provided for risk assessment, the evaluation system provides $4 \times 5$ and $4 \times 4$ matrices, but this is subject to change according to experts (contractors, supervisors, etc.), and is not clearly defined [9]. In the absence of items related to hazards, the missing factors are determined by the supervisor or expert.

In addition, the domestic design-for-safety review requires a separate evaluation of the control measures, and the details of the evaluation criteria and methods for the control measures are left to the contractor and designer, so the benefit of the evaluation is low. These problems make it difficult to apply what is currently aimed at the domestic design-for-safety review manual in the field. As a result, only the evaluation of design alternatives occurs in the actual reviews, and the risk evaluations are omitted. Thus, the evaluation is different from the one intended in the design-for-safety review task manual. This is because there are too many items required in the risk assessment process of other design-for-safety reviews. In the case of Singapore and Hong Kong, the risk assessment items required in the design-for-safety review process only require clarification of hazards, risk ratings, control measures, reduced risk ratings, and related personnel. However, in the case of design-for-safety reviews in Korea, additional results (in addition to the above items) must be prepared for the risk assessment results such as human/physical damage, control measures by third parties, whether to review, and whether additional work such as reports for review are necessary. Further, evaluations and results for control measures are required. This means that there are more items to be prepared than design-for-safety reviews in other countries, and it also means that there are insufficient guidelines.

\subsection{Result}

Domestic and international cases of the risk rating process were derived to address the challenges facing the introduction of a domestic design-for-safety review. First of all, objective evaluation is difficult in the existing process of risk assessment according to the existing safety management measures due to the reliance on experts, which results in subjectivity. This is difficult to apply in domestic construction sites because the contents of the distributed guidelines lack the evaluation criteria and evaluation methods required in the review process and there are many items to be compared with other evaluation cases. In addition, it is more difficult to secure objectivity in the case of design-for-safety review work in Korea, where many items depend on experts and contractors due to unclear guidelines. To solve this, we intend to simplify the existing domestic design-for-safety review items, recognize hazards based on BIM, and conduct risk assessments to automate risk assessment during design-for-safety reviews.

A number of studies have been conducted on domestic and foreign BIM-based risk assessment or safety management of construction projects. In Korea, only research on a BIM-based management plan and the evaluation model level has been conducted. Prior studies have been conducted to recognize hazards or conduct reviews using BIM data, but they are only at the level of presenting 
BIM-based evaluation methods [32,33]. As a preliminary research case abroad, a study on Shijie Zhung's BIM-based fall hazard recognition was conducted [10]. Based on the BIM model, an algorithm was proposed to measure the falling height for each wall object and slab object and to derive the hazard of fall accordingly. However, it stopped at the level of risk recognition and was not employed in the evaluation. In addition, various studies for safety management of construction sites have been conducted using BIM information, including the development of a method for recognizing hazards based on time information, and deriving a risk assessment system based on calculating the severity factor for the U.S. [34,35]. However, the risk assessment is limited to the level of risk recognition, so a separate method is required for risk rating estimation. In the case of risk rating estimation, a calculation process for items such as severity and frequency factor for calculating the risk level for each hazard is required. This study derives hazards through the process of BIM-based hazard recognition and derives risk assessment results by calculating the risk level based on them. We intend to conduct a design-for-safety review based on the results of the evaluation.

\section{BIM-Based Hazard Recognition}

In BIM-based risk assessment, it is necessary to define a disaster in the BIM model to derive hazards from BIM data. To this end, risk assessment cases and disaster occurrence scenarios were collected based on the risk assessment examples of disasters in domestic construction sites along with safety guidelines for each disaster and construction accident database. The factors associated with hazards in domestic construction sites and weights for control measures were derived based on the risk assessment cases [36]. A method for recognizing hazards was established based on the occurrence scenario related to the disaster. Based on this, a risk assessment item based on BIM was derived. Tables on hazards and risk grades for each disaster were prepared for inputs of the factors of occurrence, location, risk, and type of disaster occurring at the construction site. Based on this, risk assessment was performed according to the hazards derived from the BIM model. In addition, we aimed to automate the risk rating estimation of BIM-based design-for-safety review by deriving the results through a simplified risk assessment template for a design-for-safety review.

\subsection{Derivation of Risk Assessment Items (Hazard)}

Based on the collected risk assessment cases, we intend to conduct risk assessments tailored to domestic construction sites. Risk levels were derived by collecting information on the severity and frequency of occurrence for each disaster. We conducted risk assessments for fall, trip, drop (hit by object), collision, and stuck disasters, which are the most frequently occurring disasters at domestic construction sites. Items required in the existing design-for-safety review and risk assessment can be calculated by preparing and applying the control measures that can be taken for each disaster and applying the corresponding reduction weights.

\subsubsection{Collection of Risk Assessment Cases}

We evaluated cases provided in the design-for-safety review task manual, and 113 risk evaluation cases for five disasters were derived [9]. Based on this, the risk assessment results for each hazard were derived, and the contents are shown in Table 3. For example, among the disasters occurring in reinforced concrete construction, the fall disaster accounted for 54 out of 113 cases, and 14 serious accidents occurred. A serious disaster is a disaster in which the operation of the workplace is suspended or required to be improved in case of an accident with a risk rating of 4 or higher. Among the 14 serious disasters, each disaster scenario was identified and each occurrence requirement and location were considered. Among them, in the case of a fall disaster, there were risks of different values depending on the height of the fall, and the standard values of $2 \mathrm{~m}, 3 \mathrm{~m}$, and $4.5 \mathrm{~m}$ had a rating of 12 , and a height of $5 \mathrm{~m}$ or more had a rating of 8 . That is, it was judged that the height of $2 \mathrm{~m}$ or more and less than $5 \mathrm{~m}$ had a risk of 12 rating, and the height of $5 \mathrm{~m}$ or more had an 8 degree of risk. 
Table 3. Risk rating table for design-for-safety review.

\begin{tabular}{|c|c|c|c|c|}
\hline No. & Hazard List & Likelihood & Severity & Risk Rating \\
\hline \multicolumn{5}{|c|}{ Falling from Height } \\
\hline 1 & Excavation: $2 \mathrm{~m} \leq \operatorname{Height}(\mathrm{H})<6 \mathrm{~m}$ & 3 & 4 & 12 \\
\hline 2 & Excavation: $\mathrm{H} \geq 6 \mathrm{~m}$ & 2 & 4 & 8 \\
\hline 3 & $2 \mathrm{~m} \leq \mathrm{H}<5 \mathrm{~m}$ & 3 & 4 & 12 \\
\hline 4 & $\mathrm{H} \geq 5 \mathrm{~m}$ & 2 & 4 & 8 \\
\hline 5 & Opening: $\mathrm{H} \geq 2 \mathrm{~m}$ & 2 & 4 & 8 \\
\hline \multicolumn{5}{|c|}{ Drop (hit by object) } \\
\hline 1 & Hit by falling object (steel pipe scaffold) & 2 & 4 & 8 \\
\hline 2 & Hit by falling object & 3 & 4 & 12 \\
\hline 3 & Hit by falling worker & 2 & 4 & 8 \\
\hline \multicolumn{5}{|c|}{ Slip } \\
\hline 1 & Slip and trip & 2 & 3 & 6 \\
\hline 2 & Slip and fall & 2 & 4 & 8 \\
\hline \multicolumn{5}{|c|}{ Stuck } \\
\hline 1 & Stuck in construction equipment & 3 & 3 & 9 \\
\hline 2 & Worker's hand stuck & 3 & 3 & 9 \\
\hline \multicolumn{5}{|c|}{ Crush } \\
\hline 1 & Crush between workers & 3 & 4 & 12 \\
\hline 2 & Crush with construction equipment & 3 & 3 & 9 \\
\hline 3 & Crush with object & 3 & 3 & 9 \\
\hline
\end{tabular}

After applying the mitigation measures in the design-for-safety review case and the risk assessment case, the results of the risk assessment reflecting the mitigation measures are to be submitted according to the reduced risk assessment results. The weights of the likelihood and severity coefficient of each control measure were classified based on the risk assessment cases of design-for-safety review, and these are presented in Table 4. Countermeasures for falling, tripping, dropping objects (hit by object), collision, and stuck disasters, risk management of the business site is managed by adjusting the frequency of occurrence. A reduction value was set according to each item based on the change in the likelihood and severity coefficient of each control measure, and the risk assessment of the design-for-safety review will be conducted in light of the re-evaluation that accounts for the control measure in the risk assessment results.

\subsubsection{Derivation of Evaluation System for Design-for-Safety Review}

The evaluation results for each hazard and the weight values according to the control measures were derived by collecting and analyzing risk assessment cases before and after the control measures. In other words, it is possible to prepare a report on the risk assessment required by the design-for-safety review task by adding weights for each control measure to the derived risk assessment results. In addition, an evaluation template was prepared based on the evaluation items derived to support the existing risk evaluation. We intend to simplify the vast number of evaluation items, which is a problem in the existing design-for-safety review template, and evaluate the risk level by conducting a risk evaluation based on this simplification.

As previously mentioned, items that are commonly required in the existing risk assessment templates are 'hazard', 'risk assessment result', 'control measures', and 'residual risk assessment result'. The next most commonly required items include 'task or process name', and risk management entity (supervisor). Based on this, items that are not needed in the domestic design-for-safety review template include items such as physical/human damage, control measures by third parties, and residual hazard. The contents are shown in Figure 1. 
Table 4. Reduction weights by control measure

\begin{tabular}{|c|c|c|c|}
\hline \multirow{2}{*}{ Hazard } & \multirow{2}{*}{ Control Measure } & \multicolumn{2}{|c|}{ After Control } \\
\hline & & Likelihood & Severity \\
\hline \multirow{6}{*}{ Fall } & Barricades/Guard rails provided & -1 & - \\
\hline & Scaffold & -1 & - \\
\hline & Warning signs & -1 & - \\
\hline & Fall arrest system & -2 & - \\
\hline & Anchorage point & -2 & - \\
\hline & Redesign building plan for structure to eliminate the need to work at height & -2 & - \\
\hline \multirow{4}{*}{ Drop } & Provide workers with hand tool belt & -1 & - \\
\hline & Safety barrier & -1 & _- \\
\hline & Provide a toe board & -1 & - \\
\hline & Fall prevention net & -1 & - \\
\hline \multirow{3}{*}{ Slip } & Anti-slip boots provided & -1 & - \\
\hline & Handrail provided & -1 & - \\
\hline & Removal of wet area & -1 & - \\
\hline \multirow{3}{*}{ Stuck } & Design a site construction plan considering vehicle traffic lines, etc. & -1 & - \\
\hline & Securing equipment utilization space & -2 & - \\
\hline & Training for communication between workers & -2 & - \\
\hline \multirow{3}{*}{ Collision } & Conformity review with pre-simulation & -1 & - \\
\hline & Placed flagman & -2 & - \\
\hline & Prepare hypothesis layout considering worker circulation & -2 & - \\
\hline
\end{tabular}

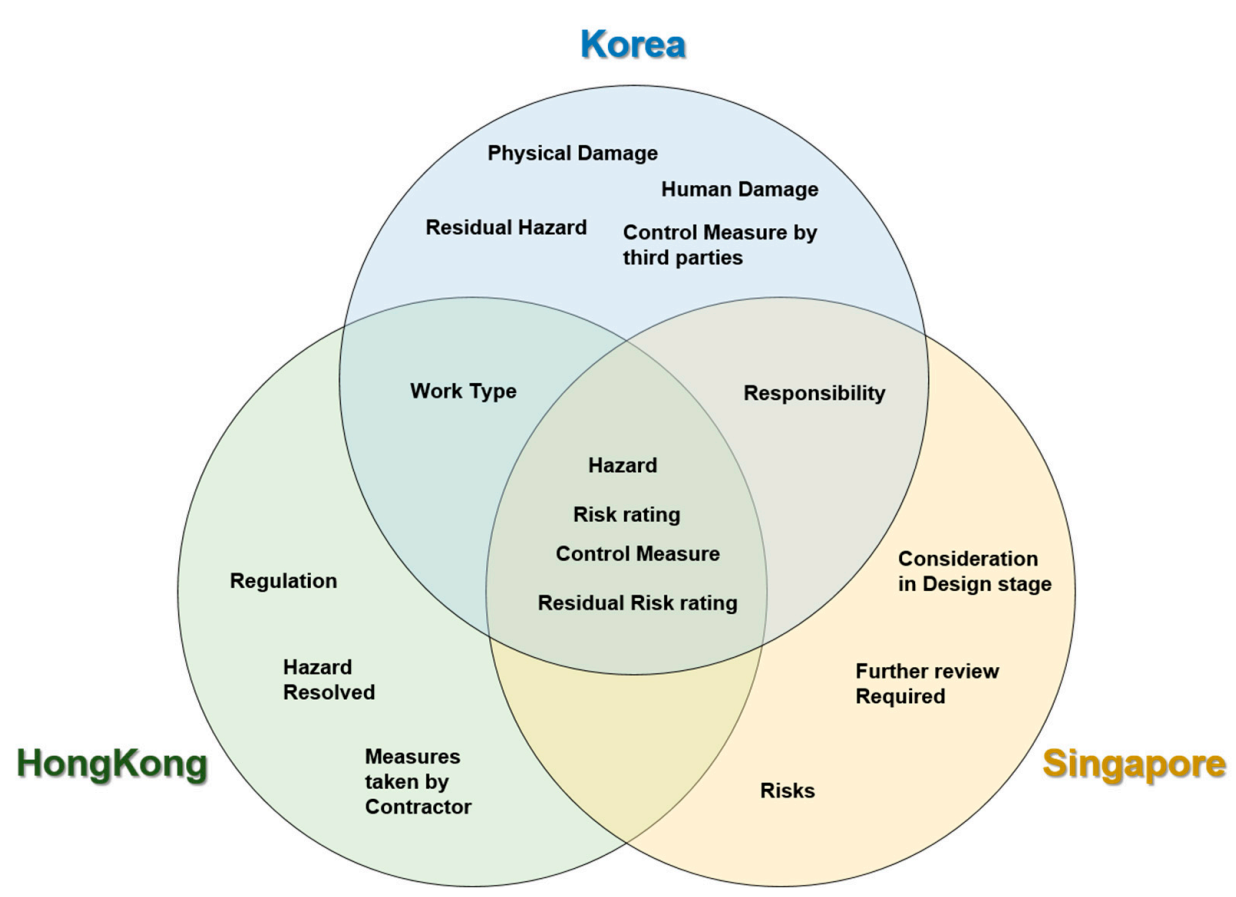

Figure 1. Design-for-safety review for different countries showing overlapping items.

We will remove unnecessary items and focus on the items that are required first, and then proceed with risk rating estimation and calculation of the reduced risk level based on the weight and the control measures. Multiple reduction measures may be applied to one disaster, and a separate method is required to express the risk assessment results of the multiple reduction measures in one report. According to domestic studies, the hazards for each construction project and the risks associated with them were measured based on the design-for-safety review cases [37,38]. Thus, if multiple control measures were used after applying each reduction measure according to the hazards in this study, the risk assessment results are expressed through the average value of the risk ratings to indicate the risk and the reduced risk of each disaster. The results of the reduced risk rating estimation based on the simplified risk assessment system for design-for-safety review are shown in Table 5 . 
Table 5. Example of design-for-safety review template.

\begin{tabular}{|c|c|c|c|c|c|c|c|c|}
\hline \multirow{2}{*}{ Hazard } & \multicolumn{3}{|c|}{ Risk } & \multirow{2}{*}{ Control Measure } & \multicolumn{3}{|c|}{ Residual Risk } & \multirow{2}{*}{ Final Risk } \\
\hline & Likelihood & Severity & Risk Rating & & Likelihood & Severity & Risk & \\
\hline \multirow{3}{*}{ Worker Fall } & \multirow{3}{*}{3} & \multirow{3}{*}{4} & \multirow{3}{*}{12} & Barricades/Guard rails & 2 & 4 & 8 & \multirow{3}{*}{ Risk $_{a v g}=6.7$} \\
\hline & & & & Anchorage point & 1 & 4 & 4 & \\
\hline & & & & Warning signs & 2 & 4 & 8 & \\
\hline
\end{tabular}

\subsection{BIM-Based Risk Rating Estimation}

To evaluate the risk rating based on BIM for the derived evaluation items, we intend to proceed with risk assessments by analyzing each disaster based on the evaluation scenario for each hazard. To estimate the risk levels of the five disasters mentioned in Section 3.1, we listed the causes of the disasters and established a method for deriving hazards. Among them, we sought to derive the results of BIM-based risk assessment through a hazard analysis of the disasters and the risk assessment method to achieve pre-safety management at the construction site through a design-for-safety review. To this end, information on the occurrence conditions, environment, and location of fall disasters was collected, hazards were derived from the BIM model, and a risk level evaluation was conducted.

\subsubsection{BIM-Based Hazard Recognition Method}

For BIM-based risk assessment, we intended to conduct an open BIM-based assessment using industry foundation classes (IFC) data, a standard information format. The evaluation was conducted based on the IFC-defined building object (IfcBuildingElement). Table 6 shows the information contained in the IFC architectural objects as examples of IFC building objects [39]. In addition, connections and other property information such as HasOpening, ConnectedFrom, and ConstraintedInStructure are also defined. A BIM-based risk assessment was conducted by minimizing additional definitions based on the basic definitions of the objects included in the sub-items of IfcBuildingElement.

Table 6. Data structure of IfcBeam object.

\begin{tabular}{|c|c|c|c|}
\hline Building Object & Definition & Name & Content \\
\hline \multirow{11}{*}{ IfcBeam } & \multirow{8}{*}{$\begin{array}{l}\text { Quantity Use } \\
\text { Definition }\end{array}$} & NominalLength & - \\
\hline & & CrossSectionArea & - \\
\hline & & OuterSurfaceArea & - \\
\hline & & TotalSurfaceArea & - \\
\hline & & GrossVolume & - \\
\hline & & NetVolume & - \\
\hline & & GrossWeight & - \\
\hline & & NetWeight & - \\
\hline & \multirow{2}{*}{ Local Placement } & IfcLocalPlacement & - \\
\hline & & $\begin{array}{l}\text { World Coordinate } \\
\text { System }\end{array}$ & - \\
\hline & Geometric Representations & $\begin{array}{c}\text { SweptSolid } \\
\text { Representation }\end{array}$ & $\begin{array}{c}\text { Solid } \\
\text { Profile } \\
\text { Extrusion }\end{array}$ \\
\hline
\end{tabular}

In the case of a fall disaster, the frequency of occurrence has a high value, and in the case of a fall disaster occurring at a low height, it shows a higher frequency. The results of the risk rating evaluation according to the height of the fall disaster are shown in Table 3. As shown, the height of the fall has a small impact on the severity of the disaster, and there is a higher risk rating when the occurrence height is lower. In other words, the severity factor of a fall disaster has a maximum value of 4 , and the frequency of occurrence is the most influential effect on this disaster. Therefore, the higher the exposure to a fall disaster is, the more dangerous it is, so a fall disaster occurring at a low height has a higher risk. 
An evaluation system was derived by collecting scenarios in which fall disasters occur to establish a scenario for evaluating the risk of fall disasters. The guidelines for preventing fall disasters distributed by the Korea Occupational Safety and Health Agency (KOSHA) were followed [40-43]. According to the item "Use a high work platform secured at a height of $2 \mathrm{~m}$ or more from the ground", it is assumed that there is a possibility of exposure to a fall disaster when working at a height of $2 \mathrm{~m}$ or more from the ground. In other words, a height of $2 \mathrm{~m}$ is the minimum condition that can cause a fall disaster. The process of deriving the risk assessment items from the BIM object is as shown in Figure 2, assuming the risk assessment conditions for the fall disaster are based on the condition of "at least $2 \mathrm{~m}$ above the ground".

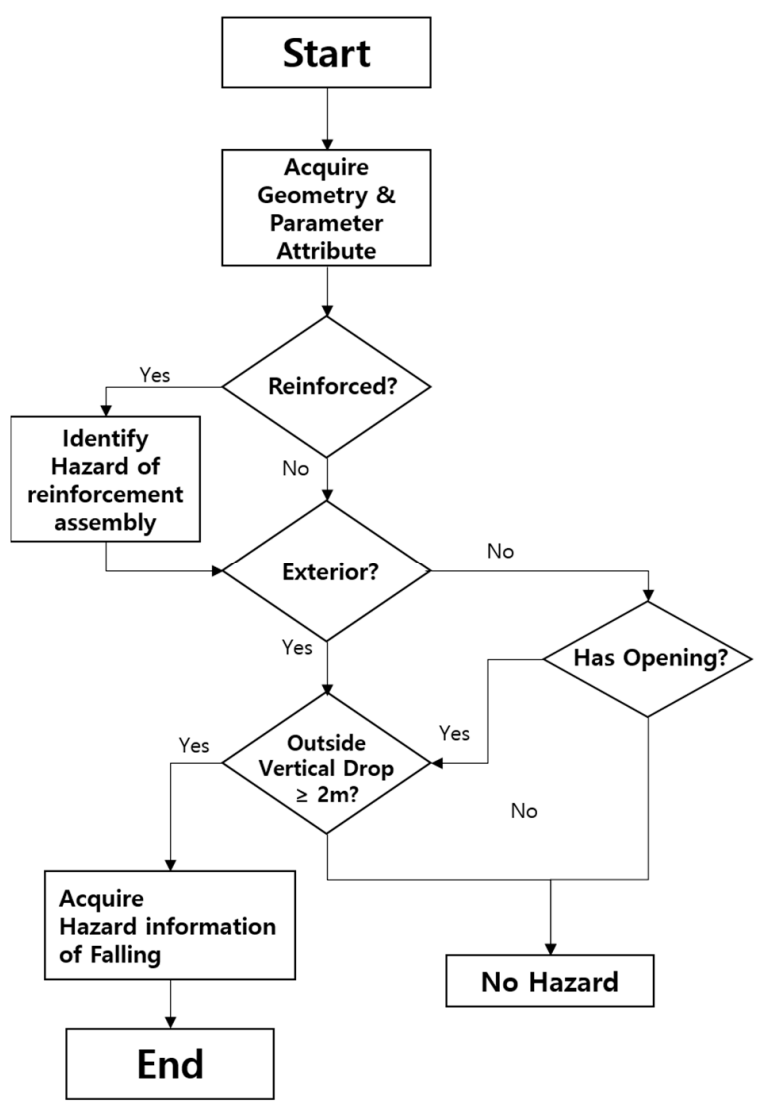

Figure 2. Fall hazard recognition algorithm.

\subsubsection{BIM-Based Hazard Recognition}

The goal of this study is to conduct a risk assessment in advance from the BIM object, and through this, it aimed to achieve inconsistent safety management, an inconsistent problem of the existing risk assessment. Among them, the risk rating can be evaluated based on the IFC data, and a separate check on the countermeasures against it can provide a measure of how to make the hazards reach an acceptable level of risk in the field.

To evaluate the risk of the BIM model, representative objects needed to represent each disaster item were selected. First, floor objects (IfcSlab), which have a high incidence of fall accidents, and fall and stuck disasters, and drop (hit by object) and trip disasters, and beam-column (IfcBeam-IfcColumn) objects are selected as representative examples. Additional construction information (e.g., column-to-beam assembly, beam-to-bottom assembly, etc.) can be derived from the connection relationship between each object, and the disasters that can be derived from the slab-column-beam object including this are shown in Table 7. 
Table 7. Result of derived hazards for each IFC object.

\begin{tabular}{cccc}
\hline Object & Type & Hazard & Detail \\
\hline \multirow{4}{*}{ IfcBeam } & Reinforced concrete & Fall & Assembly on steel structure \\
& Reinforced concrete & Stuck & $\begin{array}{c}\text { Assembly on steel structure } \\
\text { Carry steel bar }\end{array}$ \\
& Reinforced concrete & Crush & $\ldots$ \\
\hline \multirow{5}{*}{ IfcWall } & $\ldots$ & $\ldots$ & Assembly on steel structure \\
& Reinforced concrete & Fall & Carry steel bar \\
& Reinforced concrete & Stuck & Assembly on steel structure \\
& Reinforced concrete & Drop & $\ldots$ \\
\hline \multirow{3}{*}{ IfcColumn } & $\ldots$ & $\ldots$ & Assembly on steel structure \\
& Reinforced concrete & Stuck & Carry steel bar \\
& Reinforced concrete & Drop & Carry steel bar \\
& Reinforced concrete & Crush & $\ldots$ \\
\hline \multirow{2}{*}{ IfcSlab } & $\ldots$ & $\ldots$ & Assembly on steel structure \\
& Reinforced concrete & Stuck & \\
& Reinforced concrete & Slip & Working on opening \\
& Reinforced concrete & Fall & $\ldots$ \\
\hline
\end{tabular}

Among the derived items, the items required in the design-for-safety review process were preferentially marked. Overall, this study supports the risk rating estimation process required during the design-for-safety review process using BIM data to facilitate the task. BIM can be used as a quantitative indicator of safety management in construction sites by deriving hazards from BIM objects and conducting risk assessment according to risk rankings.

\section{Design-for-Safety Review through BIM-Based Risk Assessment}

\subsection{Simplification of Derived Hazards}

These hazards are derived by object unit through the relationship between the slab, column, and beam objects and object property information. However, the existing risk assessment is a hazard of the working type unit rather than the object unit. That is, it is difficult to use the currently derived hazard items for risk assessment. To this end, the duplicated hazards were removed, and the hazards were reorganized in units of hazards by working type. The contents are shown in Table 8 .

Table 8. Derived risks by hazards for design-for-safety review.

\begin{tabular}{cccc}
\hline No. & Process & Hazard & Risk \\
\hline 1 & Reinforcement concrete work & Falling during rebar assembly & Fall $(2.5 \mathrm{~m})$ \\
2 & Reinforcement concrete work & Stuck during rebar assembly & Stuck \\
3 & Reinforcement concrete work & Drop the rebar during rebar assembly & Drop \\
4 & Reinforcement concrete work & Drop the rebar during carrying rebar & Drop \\
5 & Reinforcement concrete work & Collision between workers & Collision \\
6 & Reinforcement concrete work & Worker-equipment collision & Collision \\
$\ldots$ & $\ldots$ & $\ldots$ & $\ldots$ \\
\hline
\end{tabular}

Hazards were reclassified according to the work by industry type, and hazards for risk assessment in the design-for-safety review were derived. Details associated with a disaster are based on the occurrence of the disaster, and these are used to calculate the risk rating for the derived hazards. In the case of the 'crash disaster during pour work', a secondary disaster, being stuck, occurred due to a collision. That is, in the case of a disaster having a plurality of hazards among the derived items, the risk level for each disaster was calculated, and then the evaluation was conducted based on the hazard with the highest risk level. 


\subsection{Risk Rating Estimation Based on Derived Hazards}

Among the hazards derived above, the risk of a disaster also varies depending on the environment in which it occurred. For example, the severity and likelihood coefficient of the disasters occurring at a height of $2 \mathrm{~m}$ and a disaster at a height of $4 \mathrm{~m}$ should be different. That is, a risk estimation method is required based on variables such as height to derive a separate risk assessment result according to the situation. The criteria that are classified based on risk assessment cases for domestic construction sites have separate risk ratings for "more than $2 \mathrm{~m}$ " and "more than $6 \mathrm{~m}$ ". In other words, in the fall disaster, the height variable affects the risk rating. The algorithm for the risk assessment process reflecting this is shown in Figure 3. The process of risk assessment of a fall disaster occurring during ground work is shown based on the method for estimating the risk level according to the disasters defined above.

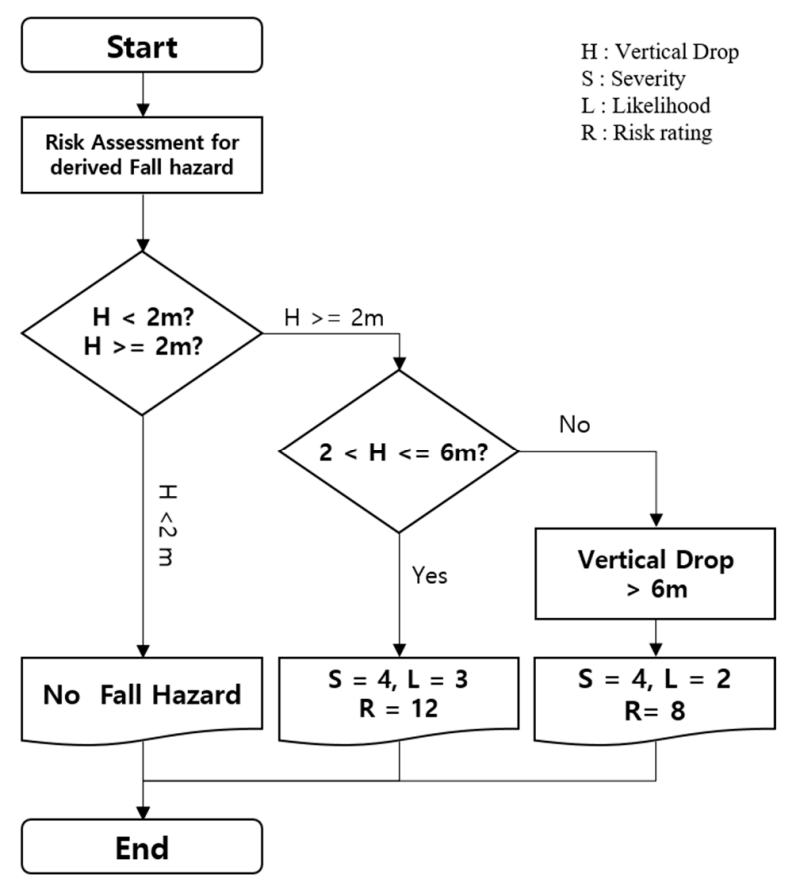

Figure 3. Algorithm of risk rating estimation by fall height.

The purpose of this study is to show the results of the risk assessment for falling/trip/drop (hit by object)/collision/stuck disasters depending on the hazards. In other words, by showing the result of the risk assessment, it is possible to derive hazards and risks that may occur in the construction site from the design stage, thereby enabling more objective and efficient safety management. Control measures must be established to lower the risk to an acceptable level when managing the calculated risk assessment results. In other words, the control measures for each hazard should be applied during the review. Table 9 shows the results after risk assessment is performed when applying each control value as mentioned in Table 4.

A risk assessment of the hazards recognized in the design stage was conducted to review the design-for-safety of selected disasters. The design-for-safety review and risk assessment were conducted based on examples of the five disasters. The results of this evaluation allowed us to extract unacceptable hazards according to the risk assessment criteria and determine the unacceptable hazards based on the risk level after controls were applied. Hazards should be eliminated by applying a separate control measure or design change, and the hazards were derived based on the BIM model. A design-for-safety review was conducted by preparing risk assessment and control measures for each hazard, and it was possible to extract even unacceptable hazards based on the final risk assessment criteria. In this manner, BIM-based risk assessment system was implemented through systematization. 
Table 9. Result of BIM-based risk assessment for design-for-safety review.

\begin{tabular}{|c|c|c|c|c|c|c|c|c|}
\hline \multirow[b]{2}{*}{ No. } & \multirow[b]{2}{*}{ Process } & \multirow[b]{2}{*}{ Hazard } & \multicolumn{3}{|c|}{ Risk } & \multicolumn{2}{|l|}{ Residual Risk } & \multirow[b]{2}{*}{ Responsibility } \\
\hline & & & $\begin{array}{l}\text { Likelihood } \\
\text { (L) }\end{array}$ & $\begin{array}{l}\text { Severity } \\
\text { (S) }\end{array}$ & Risk Rating & Control Measure & $\begin{array}{c}\text { Residual } \\
\text { Risk Rating }\end{array}$ & \\
\hline 0 & 00 work & 00 & $\mathrm{~L}$ & $\mathrm{~S}$ & $\mathrm{~L} \times \mathrm{S}$ & $\begin{array}{l}A_{1} \\
A_{2} \\
\ldots \\
A_{n}\end{array}$ & $\frac{\sum_{i}^{n} A_{i}}{n}$ & 000 \\
\hline 1 & Temporary work & Worker fall at opening & 2 & 4 & 8 & $\begin{array}{l}\text { Fall arrest system } \\
\text { Warning sign }\end{array}$ & 4 & Constructor \\
\hline 2 & Construction equipment work & Collision between workers & 3 & 4 & 12 & $\begin{array}{c}\text { Pre-simulation } \\
\text { Prepare hypothesis layout }\end{array}$ & 6 & Designer \\
\hline 3 & Reinforcement concrete work & Worker fall (3 m height) & 3 & 4 & 12 & $\begin{array}{l}\text { Barricade Guard rail } \\
\text { Anchorage point } \\
\text { Warning signs }\end{array}$ & 6.7 & Constructor \\
\hline 4 & Reinforcement concrete work & Material drop & 3 & 4 & 12 & $\begin{array}{c}\text { Safety barrier } \\
\text { Toe board } \\
\text { Fall prevention net }\end{array}$ & 8 & Constructor \\
\hline 5 & Reinforcement concrete work & $\begin{array}{l}\text { Worker's hand stuck in } \\
\text { equipment }\end{array}$ & 3 & 3 & 9 & $\begin{array}{l}\text { Securing equipment utilization space } \\
\text { Prepare hypothesized layout }\end{array}$ & 4.5 & $\begin{array}{l}\text { Designer, } \\
\text { Constructor }\end{array}$ \\
\hline
\end{tabular}




\subsection{Implementation of BIM-Based Risk Assessment System}

To calculate the risk rating, disasters that could occur at the construction site were extracted, and the severity and likelihood coefficients were calculated for the risk class. We developed a derivation process for hazard recognition and a review template for field application using the BIM model. Finally, to automate the design-for-safety review, IFC-based hazard extraction, risk rating estimation, and risk re-calculations were performed accounting for control measures. Prior to implementing the existing risk rating results required in the design-for-safety review, control measures were implemented and calculations of the reduced risk rating according to the control measures were performed. Control measures were selected by consulting experts, and multiple control measures or a single control measures were applied depending on the characteristics of the site and supervision of experts. In other words, it provides the results of the risk assessment of existing disasters, but the application of each reduction measure requires direct input. For the application of each reduction measure, a system was constructed based on a template in the form of a checklist, and the overall risk of building can be derived by reflecting the risk level according to each reduction measure. Through this, the risk assessment process in the safety management process can be conducted based on BIM. The results are shown in Figures 4 and 5.

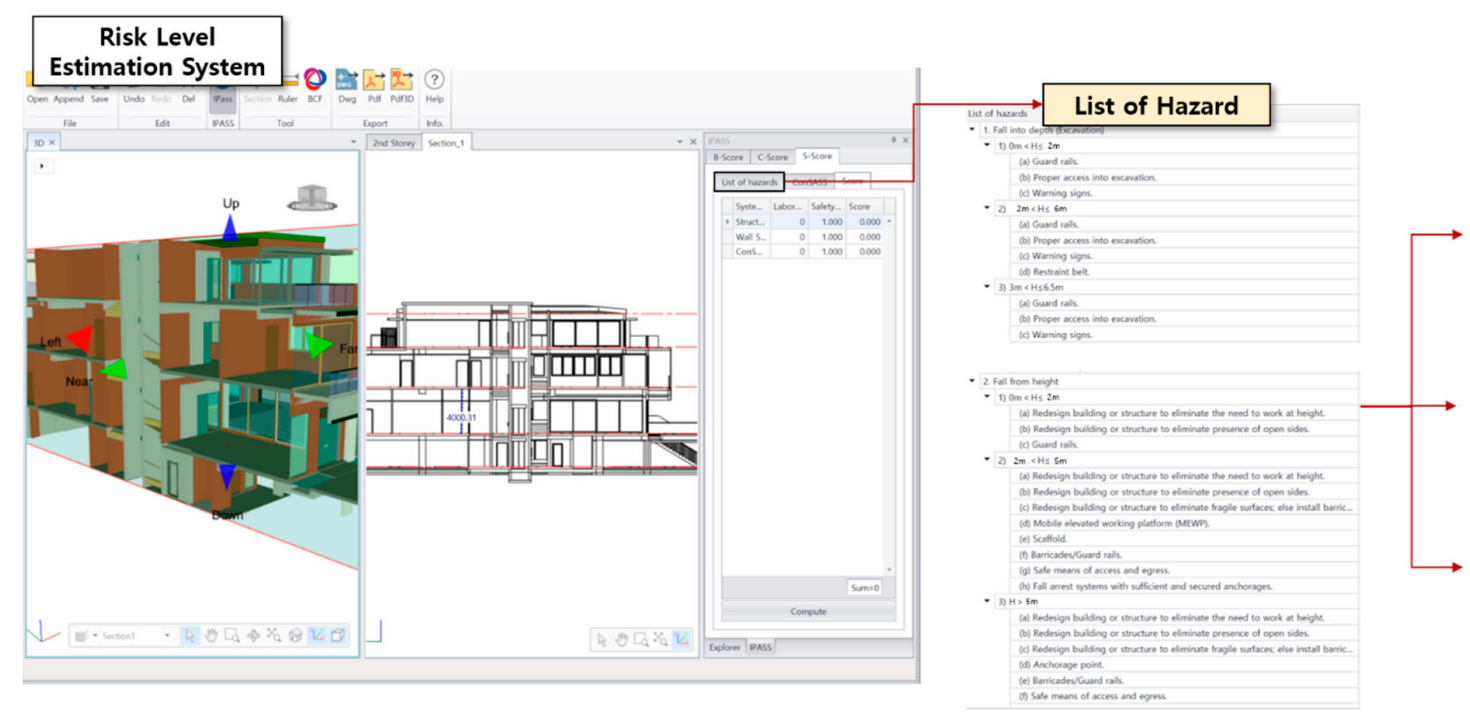

Figure 4. Results of the BIM-based risk assessment system.

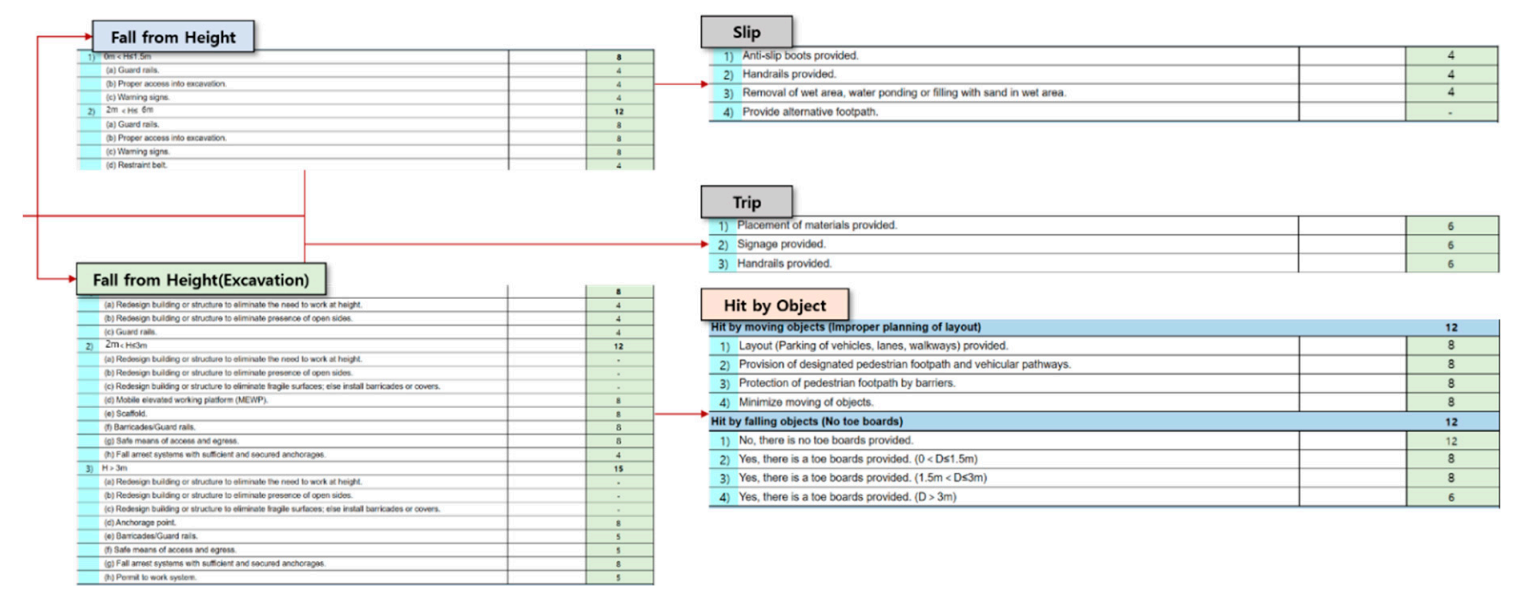

Figure 5. Results of the BIM-based risk assessment system (continue). 
Currently, 29 types of hazards have been identified, and the priority levels for the five hazards presented in this study were calculated. We intend to proceed with estimating the risk level by providing the existing risk level and reduced risk level. In addition, it is possible to visually check objects according to each disaster condition based on 3D and 2D views. However, this is challenging for some disasters, and a report calculation function should also be linked with the design-for-safety review template. In addition, automation of the design-for-safety review can be achieved by implementing a function that can show the occurrence site based on the evaluation results and the object in which each disaster occurs.

Using this system, hazards were extracted from the BIM model, and the risk rating was calculated accordingly. Based on the calculated results, it is possible to automate the preparation of the risk rating and recalculation results of the design-for-safety review template by recalculating the risk rating for each control measure. In the case of a fall disaster, different results are obtained depending on the height of the disaster. BIM is used to automatically detect this according to the height of the object and conduct the evaluation accordingly. In other words, the recognition of hazards that were previously achieved by expert observation was automated. The risk assessment process was automated by calculating the risk rating based on the recognized hazards and applying reduction values for the control measures. That is, it is possible to increase the consistency and accuracy of the design safety review by automating the risk assessment task of the design safety review task. Among the existing design-for-safety review tasks, it is possible to accelerate the introduction of design-for-safety by automatically calculating quantitative indicators used as main indicators. The scenario of occurrence of each disaster does not differ greatly from country to country, and only the standard of occurrence is different. For example, in the case of Korea, the condition of the fall disaster is $2 \mathrm{~m}$ or more, but in Singapore, it is assumed that the fall may occur at a height of $1.5 \mathrm{~m}$ or more. In other words, it is considered that it is possible to apply a wide range of customization by providing a ruleset for each disaster-related evaluation system developed in the risk assessment system. However, the limited scope of the evaluation will also need to be expanded through the collection of continuous evaluation cases, and if continuous expansion and development are achieved, it will be possible to review the level of design-for-safety applicable to the field.

\section{Conclusions}

To safely manage construction sites with a high incidence of accidents, the government introduced the concept of design-for-safety to manage and control accident occurrence factors in the design-construction phase. However, the design-for-safety review has not been applied due to its hasty introduction, in which legislators neglected to consider the existing safety management tasks. Thus, the content of guidelines are insufficient, and therefore they cannot be applied in practice. Other countries introduced the concept beginning in 2006-2007, while the legal and practical research in Korea are still insufficient in terms of time and cost.

Therefore, this study was conducted to solve the problem of 'inconsistent risk assessment', one of the major problems in the risk assessment process among the existing construction site safety management tasks. To this end, cases of construction site safety management at home and abroad were collected and analyzed and classified based on each country's characteristics. Also, we sought to develop a more efficient and accurate risk assessment by applying automation using BIM technology. As part of this, we conducted a literary and theoretical review of the BIM information, risk assessment process, and design-for-safety review method, and we found the following problems.

First, Korea lacks a database on domestic safety management. In other countries, there are about 1600 PtD evaluation lists in the United States and 1200 items in Singapore ConSASS [20,44]. Accordingly, a separate certification system is operated, and the evaluation system has been applied to the construction industry by fostering partners and experts for this purpose. However, only safety accident reports are provided in Korea, and there are only 34 items organized for separate checklists, 
evaluation items, and evaluation cases. Due to these problems, the safety management of domestic construction sites is fixed and very formal.

Second, Korea lacks clear criteria for the domestic risk rating process. For example, KOSHA's guidelines are based on a $4 \times 5$ matrix, and various risk criteria have been established. However, the Ministry of Land, Infrastructure and Transport's guidelines are based on a $4 \times 4$ or $4 \times 5$ matrix, which causes great confusion in obtaining information [2,9]. In this situation, domestic construction sites perform safety management at the discretion of the safety supervisor, resulting in inconsistencies.

Therefore, to solve the above problems, we defined items related to hazard recognition based on foreign cases in this study, and utilized this for evaluations in design-for-safety. Using this method, consistent risk assessment is possible based on digital data such as BIM, thereby increasing the reliability of the risk assessment results. As a result, the quality of safety management at the construction site will be improved. Lastly, safety management work efficiency will increase if the reliability of the evaluation results can be ensured and applied to the actual construction site safety management work.

In this study, we proposed a BIM-based risk factor recognition method, hazard extraction, and the risk rating estimation method for the extracted items. However, the scope of risk assessment is limited due to the lack of examples of risk assessment, and it is difficult to apply to cases where risk assessment is conducted across all areas of the construction industry. However, as mentioned above, if we continuously accumulate evaluation data on safety management and development of risk assessment guidelines with clear standards, then the BIM-based risk assessment system can be expanded. In addition, it is necessary to implement technology so that it can be used in practice through the development of systems or applications. In addition, through the provision of this risk assessment ruleset, customization will be possible to apply the standards of other countries, and it will be expanded to be applicable in various countries as well as Korea. It is necessary to develop a system that can be applied within the general construction process as well as design-for-safety risk assessment by enabling a wider risk assessment through risk assessment cases in various countries.

Author Contributions: Conceptualization, Y.L.; data curation, Y.L. and J.C.; formal analysis, Y.L., I.K. and J.C.; funding acquisition, I.K. and J.C.; investigation, Y.L. and J.C.; methodology, Y.L., I.K. and J.C.; project administration, I.K.; resources, Y.L., I.K. and J.C.; supervision, I.K.; validation, Y.L., I.K. and J.C.; visualization, Y.L. and J.C.; writing-original draft, Y.L. and I.K.; writing-review and editing, J.C. All authors have read and agreed to the published version of the manuscript.

Funding: This research was supported by a grant (20AUDP-B127891-04) from the Architecture \& Urban Development Research Program funded by the Ministry of Land, Infrastructure and Transport of the Korean government. This work was supported by the National Research Foundation of Korea (NRF) grant funded by the Korea government (MSIT) (No. NRF-2019R1F1A1062851).

Conflicts of Interest: The authors declare no conflict of interest.

\section{References}

1. Oh, B.S. Risk Assessment; Korea Occupational Safety and Health Agency: Seoul, Korea, 2005.

2. Bang, J.D.; Sohn, J.R.; Cho, G.H.; Kim, J.W.; Noh, Y.Y.; Lee, K.R.; Kim, S.M.; Ki, J.I. Improvement of Safety Management Guideline for Accident Prevention in LH Construction Site; Land \& Housing Institute: Daejeon, Korea, 2016.

3. Hong, S.H. A Construction Safety Management Information Model using the Concept of Design for Safety. J. Constr. Eng. Manag. 2004, 9, 109-116.

4. Yu, J.H.; Song, J.W.; Kim, C.D. Construction Safety Management Using FMEA Technique for Selecting Priority order. J. Constr. Eng. Manag. 2008, 9, 185-193.

5. Department of Defense. MIL-STD-882E. Available online: http://everyspec.com/MIL-STD/MIL-STD-08000899/MIL-STD-882E_41682/ (accessed on 23 April 2020).

6. Kim, Y.G. Design for Safety (DfS) Review System Enhancement Plan for Strengthening Construction Safety. Constr. Eng. Manag. 2019, 20, 16-21.

7. Ahn, H.S. Significance and implementation of the introduction of the DfS (Design for Safety) system. Constr. Eng. Manag. 2019, 20, 5-8. 
8. Levitt, R.E.; Samelson, N.M. Construction Safety Management, 2nd ed.; Wiley: Hoboken, NJ, USA, 1993; pp. 49-108.

9. Ministry of Land, Infrastructure and Transport. Design for Safety Task Manual; Ministry of Land, Infrastructure and Transport: Sejong-si, Korea, 2017.

10. Ministry of Land, Infrastructure and Transport. Design of Safety Review Report Review Casebook; Ministry of Land, Infrastructure and Transport: Sejong City, Korea, 2019.

11. DHHS(NIOSH). Prevention through Design Initiative; Publication No. 2016-130; DHHS(NIOSH): Washington, DC, USA, 2016.

12. Rajendran, S. Sustainable Construction Safety and Health (SCSH) Rating System; Version 1.0; Oregon State University: Corvallis, OR, USA, 2006.

13. Health and Safety Executive. Workplace (Health, Safety and Welfare) Regulation 1992; Guidance on Regulations; HSE: London, UK, 1992.

14. Health and Safety Executive. Construction (Design and Management) Regulation 2015; Guidance on Regulations; HSE: London, UK, 2015.

15. Health and Safety Executive. Health and Safety in Construction; HSE: London, UK, 2006.

16. Health and Safety Executive. Construction Phase Plan (CDM 2015). What you Need to Know as a Busy Builder; HSE: London, UK, 2015.

17. WSH Council. Guidelines on Design for Safety in Buildings and Structures; WSH Council: Singapore, 2008.

18. WSH Council. Workplace Safety and Health Guidelines Design for Safety; WSH Council: Singapore, 2016.

19. Ministry of Manpower. A Guide to the Construction Safety Audit Scoring System; Ministry of Manpower: Singapore, 2013.

20. Ministry of Manpower. ConSASS Checklist \& Score Board. Available online: http://mom.gov.sg/ (accessed on 23 April 2020).

21. Development Bureau. Guidance Notes of Design for Safety; Development Bureau: Hong Kong, China, 2013.

22. Development Bureau. Worked Examples of Design for Safety; Development Bureau: Hong Kong, China, 2013.

23. Australian Safety and Compensation Council. Guidance on the Principles of Safe Design for Work; Australian Government: Canberra, Australia, 2006.

24. Safe Work Australia. Safe Design of Structures Code of Practice; Workcover NSW: Gosford, Australia, 2014.

25. Schulte, P.A.; McKernan, L.T.; Heidel, D.S.; Okun, A.H.; Dotson, G.S.; Lentz, T.J.; Geraci, C.L.; Heckel, P.E.; Branche, C.M. Occupational safety and health, green chemistry, and sustainability: A review of areas of convergence. Environ. Health 2013, 12, 31. [CrossRef] [PubMed]

26. Dylan, H.; Matthew, H. Construction hazard prevention through design: Review of perspectives, evidences, and future objective research agenda. Saf. Sci. 2019, 120, 517-526.

27. Vineeth, D.; John, A.G.; Joe, F.; Ali, M.V. Quantification and Assessment of Safety Risk in the Design of Multistory Buildings. J. Constr. Eng. Manag. 2015, 141, 04014090.

28. Zhang, S.; Sulankivi, K.; Kiviniemi, M.; Romo, I.; Eastman, C.M.; Teizer, J. BIM-based fall hazard identification and prevention in construction safety planning. Saf. Sci. 2015, 72, 31-45. [CrossRef]

29. Zhang, S.; Teizer, J.; Lee, J.K.; Eastman, C.M.; Venugopal, M. Building Information Modeling (BIM) and Safety: Automatic Safety Checking of Construction Models and Schedules. Autom. Constr. 2013, 29, 183-195. [CrossRef]

30. Kim, K.; Cho, Y.; Zhang, S. Intergrating work sequences and temporary structures into safety planning: Automated scaffolding-related safety hazard identification and prevention in BIM. Autom. Constr. 2016, 70, 128-142. [CrossRef]

31. Lee, G.J. DfS(Design for safety) review support system development plan. Constr. Eng. Manag. 2019, 20, 22-25.

32. Kim, E.H. A Study on the Critical Safety Management Buildings and factors by Analyzing the Actual State of Building Safety Management. J. Archit. Inst. Korea Plan. Des. 2019, 35, 37-44.

33. Choi, B.; Lee, H.S.; Park, M.; Cho, Y.K.; Kim, H. Framework for Work-Space Planning Using Four-Dimensional BIM in Construction Projects. J. Constr. Eng. Manag. 2014, 140, 04014041. [CrossRef]

34. Dharmapalan, V. Risk Factor Quantification of Design Elements for Multistory Commercial Office Buildings; Oregon State University: Corvallis, OR, USA, 2012.

35. Rajendran, S. Sustainable Construction Safety and Health Rating System; Oregon State University: Corvallis, OR, USA, 2007. 
36. Ministry of Land, Infrastructure and Transport. Construction Safety Management Information System (COMIS). Available online: https://www.cosmis.or.kr (accessed on 4 January 2020).

37. Ji, K.H.; Choi, B.J. A Study on safety improvement of Underground wall construction to Design for Safety. Korea Acad. Ind. Coop. Soc. 2019, 20, 56-68.

38. Kim, J.W.; Kim, J.J. Disaster Risk Assessment by Work Unit of Construction Work for Improve the Efficiency of Design for Safety Task. J. Archit. Inst. Korea Struct. Constr. 2018, 34, 45-53.

39. IFC 2x3 Edition Technical Corrigendum 1. BuildingSMART. Available online: http://www.buildingsmarttech.org/ifc/IFC2x3/TC1/html/index.htm (accessed on 16 April 2020).

40. Park, G. Let's Halve the Fall Disaster; Korea Occupational Safety \& Health Agency: Seoul, Korea, 2008.

41. Park, G. Let's Halve the Stuck Disaster; Korea Occupational Safety \& Health Agency: Seoul, Korea, 2008.

42. Park, G. Let's Halve the Drop Disaster; Korea Occupational Safety \& Health Agency: Seoul, Korea, 2008.

43. Park, G. Let's Halve the Slip \& Trip Disaster; Korea Occupational Safety \& Health Agency: Seoul, Korea, 2008.

44. Prevention through Design List. Occupational Safety and Health Administration (OSHA). Available online: https://designforconstructionsafety.org/design-tools/ (accessed on 23 April 2020).

(C) 2020 by the authors. Licensee MDPI, Basel, Switzerland. This article is an open access article distributed under the terms and conditions of the Creative Commons Attribution (CC BY) license (http://creativecommons.org/licenses/by/4.0/). 